\title{
On the landscape of youth participation in science policy
}

\author{
Shashank Agarwal ${ }^{1, *}$ and Richard D. Sung ${ }^{2, *}$ \\ Edited by Kseniya Pirnavskaya and Yana Petri
}

\section{HIGHLIGHTS}

- The youth have the right and the potential to contribute to policy building and implementation.

- Youth participation not only significantly improves policies but also helps the youth to grow as mature and responsible citizens.

- However, youth participation remains largely lacking, and there is an urgent need for further promoting it.

- There is a need for timely and extensive research for identifying the most effective ways of increasing youth involvement in the policy.

Despite being important policy stakeholders, the youth remain largely absent from policy building and implementation. However, the growing literature has vividly illustrated the capacity of the youth from diverse age groups to make meaningful contributions to policy. In particular, university students are emerging as significant actors in science policy owing to their unique perspectives and knowledge. By drawing from the literature, we emphasize that the youth are capable of directly contributing to diverse policy matters while also indirectly benefiting from their participation. Consequently, there is a crucial need for initiating programs for promoting youth participation. Furthermore, to ensure the fruitfulness of such programs, more systematic research ought to be done with regards to the accomplishments and challenges of youth participation.

\section{INTRODUCTION}

$\mathbf{T}$ oday, science plays a vital role in ensuring that public policies promote the wellbeing and sustainable development of society. Science not only establishes the epistemic accountability of policy decisions, but also provides the means for guiding the design, implementation, and

${ }^{1}$ Department of Mechanical Engineering, Massachusetts Institute of Technology, Cambridge, MA, USA

${ }^{2}$ Graduate School of Science and Technology Policy, Korea Advanced Institute of Science and Technology (KAIST), Daejeon, South Korea

*Emails: ssnk_agl@mit.edu and dhsung91@kaist.ac.kr

The authors declare no conflict of interest.

(C) 2021 The Author(s) evaluation of policies. In general, science policy is understood as the "allocation of resources for the conduct of science towards the goal of best serving the public interest" [1], and numerous examples such as the Green revolution [2], child vaccination [3], the ban on ozone-depleting products [4], and ordaining the use of masks in response to the COVID-19 pandemic [5] readily illustrate the benefits of incorporating science into public policy decisions, particularly in regards to policy design. However, as it is important to use adequate tools for designing and evaluating policies, promoting sustained participation of all relevant policy stakeholders is also essential to meaningful policy action. Recently, policy experts have begun to increasingly argue for fostering youth participation in science policy [6]-[8], but such a development remains closer to a desideratum and far from reality. Moreover, this limitation is exacerbated by the lack of in-depth understanding of the accomplishments, potential, and challenges of youth participation in science policy. In this article, we explore what the youth around the world have achieved as policy actors while introducing a growing literature on the needs and advantages of youth participation in science policy.

THE YOUTH AND CONVENTIONAL POLICY BUILDING

According to the UN, an organization working at the forefront of promoting youth participation in policy around the world, an individual in transition from childhood to first employment may be considered as a youth. In addition, the age group of 15-24 years is generally considered to comprise the youth [9]. Although the exact age bracket may vary depending on the country or the legal context to be considered, university graduate students, who go beyond this age limit, can still be considered as youth by virtue of the fact that they are in the mentioned state of transition. Thus, the term "youth" includes those at various stages of life including high-school children, pre- and post-college students, and graduates in search of employment.

The idea of the youth as a major policy stakeholder raises the following questions: Are the youth not already part of public policy? If not, why? How are science policies conventionally designed and implemented? Can youth participation really help policy building? If yes, how can their participation be meaningfully promoted? 
Traditionally, policy building is considered to be the work of policy experts. While it is hardly questionable that policymaking requires expertise from various fields, building just policies is not possible without the sustained participation of all relevant stakeholders. Policy-building processes in the majority of representative democracies around the world [10] rely on public representatives who are tasked with voicing the concerns of the public that includes the youth. However, with the increase in world population, widening of wealth gaps, and the complexity of social interests, making fair and just policies through the conventional approach is becoming increasingly difficult. Cases of ignoring public feedback on policies $[11,12]$ and dubious epistemic practices blocking journalistic reporting on specific topics (such as environmental issues) have recently emerged as sources of public concern and frustration [13]-[15]. Thus, there is a growing consensus [6] that direct incorporation of insights unique to under-represented, non-expert stakeholders can improve the effectiveness and accountability of public policy.

As important stakeholders, the youth have a lot to offer to science policy building. Since the youth are affected by policies in various ways as children, adolescents, and university students, they are capable of providing diverse yet versatile perspectives and expectations which experts and other policy stakeholders cannot provide. Indeed, studies have shown that youth can bring unique perspectives and offer creative solutions to policy building especially which directly affect them $[7,8]$. Similarly, an important part of the youth, namely university students, are readily exposed to novel scientific knowledge as a part of their professional training. Their knowledge and skills, combined with a lack of bias stemming from professional obligations and interests, enable them to act as important actors who directly contribute to science policy. Furthermore, the youth today possess powerful communication skills that can be harnessed to effectively connect and mobilize diverse social groups to promote civic and political engagement [16]. In addition, policy scholars have begun to recognize the indirect benefit of youth participation in public policy in recent years. As they convincingly argue, youth participation provides the youth an opportunity to develop a sense of agency as policy actors, thus helping them become responsible citizens.

Thus, considering the limitations of conventional policy building processes, it is time that they are adaptively improved through more participatory approaches. Such approaches have become conceivably feasible, thanks to ongoing breakthroughs in communication and information technology (e.g. the internet and social media). In the following sections, we explore the current terrain of youth participation in science policy.

\section{DIRECT CONTRIBUTIONS OF YOUTH PARTICIPATION IN SCIENCE} POLICY

While the achievements and challenges of youth participation in science policy remains a nascent area of research, emerging accounts and case studies demonstrate the potential and value of youth participation. A helpful starting point in this regard is the United Nations Convention on the Rights of the Child (UNCRC) of 1989 [17]. According to Article 12 of UNCRC, signee nations have the obligation to provide opportunities for the youth to express their opinions and to incorporate them into policy decisions. As a result, there has been a notable increase in youth participation in public policy in recent years. A study on resilience-oriented urban planning in Mexico City, Boulder (US), and Thessaloniki (Greece) showed that the youth can significantly contribute to urban planning by identifying ways in which infrastructures can be built to support vulnerable social groups such as the homeless and themselves [18]. A study of the Growing Up in Cities (GUIC) program of UNESCO and the Child Friendly Cities Initiatives (CFCI) of UNICEF also made similar observations in Denver (USA) [19]. Similarly, with examples from eight nations and four continents, a recent study [20] shows that given adequate scientific means (such as statistical data analysis tools, and access to population and land data) and proper adult supervision, the youth can greatly improve policy planning at multiple levels of urban planning ranging from relatively small settings such as a schoolyard to larger settings such as neighborhood networks. Furthermore, some studies [21,22] suggest that, in certain scenarios, the youth and the general public can be more efficient in carrying out policy-related tasks than those typically considered to be policy experts.

Similarly, diverse accounts of youth participation in disaster risk reduction (DRR), public health policy, and environmental protection around the world, illustrate that the youth can directly contribute to science policy. For instance, the Philippines has promoted youth participation through several national policies since 1974, with a notable case being Sangguniang Kabataan (youth councils) [23]. As part of the DRR effort, the youth councils significantly augmented their respective region's capacity to respond to potential disaster scenarios. For example, the participating youth made use of their knowledge and communication skills to successfully persuade school officials and community planners to relocate their school which had been located in high-risk landslide zones [23]. At the same time, the youth councils have contributed to global efforts to design effective DRR measures such as the Third UN World Conference on Disaster Risk Reduction (WCDRR) in 2015 [24]. Beyond the context of DRR, youth participation has also made tangible contributions to public health policy and environmental protection. For instance, youth participation in planning and implementation has been found to greatly benefit public health programs such as Youth Engagement and Action for Health (YEAH!), a youth advocacy curriculum for promoting healthy lifestyles in the US [25]. Similarly, a recent study [26] on a community and citizen science (CCS) program in the San Francisco Bay Area, California, reports that the youth participants have significantly contributed to scientific and socio-economic studies of social-ecological systems through activities such as 


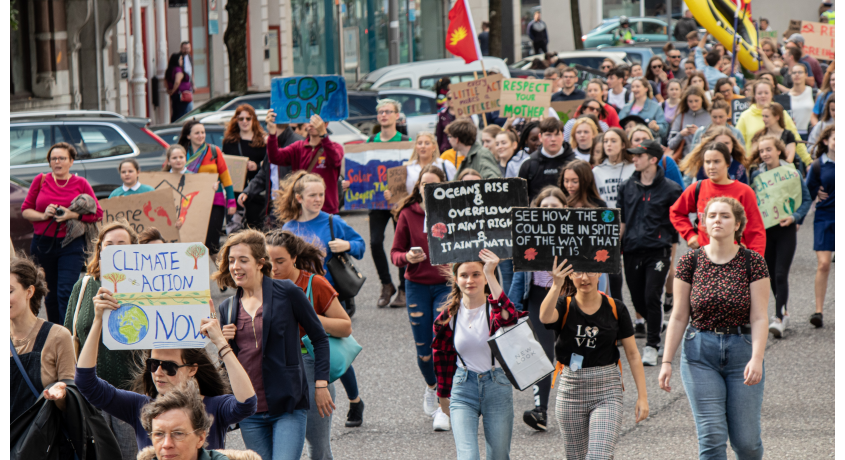

Figure 1: The youth is increasingly participating in climate action activism across the world, photo credit: [33].

ensuring rigorous data collection and disseminating scientific findings.

While such cases are certainly illuminating, university students, both undergraduate and graduate, also deserve particular attention. By virtue of their education and access to resources such as the scientific and technological literature, professional networks, and media outlets, university students represent the relatively more resourceful and well-trained youth in society. In recent years, university students are playing increasingly larger and active roles as public figures [27] as well as members of organizations that tackle diverse issues such as climate change [28], nuclear proliferation [29], and gender equality in science [30].

Furthermore, universities and policy organizations have begun to provide the students with opportunities for working towards common policy goals such as financial support programs [31] and scholarships [32] for promoting student works on science policy and community outreach [31,32]. While the developments discussed so far certainly illustrate the momentum that youth participation has gained, it is important to recognize that the examples represent the most recent developments of university-student participation in broader science policy contexts. Thus, we stress that empirical research such as the case studies of DDR in the Philippines could illuminate much on the accomplishments as well as emerging challenges of university-level youth participation in science policy.

INDIRECT BENEFITS OF YOUTH PARTICIPATION IN SCIENCE POLICY

We have emphasized the direct benefits of youth participation in the policy so far, yet an increasing number of policy experts emphasize the indirect benefits of increasing youth participation in the process. Most of these benefits are related to youth being a "population-at-risk" [34,35]. In the age of agenda-driven media [36]-[38] and an unregulated internet plagued by biases and fake news [39], the youth face the highest risk of becoming involved in antisocial behavior $[34,35]$. In this context, youth participation is increasingly garnering attention as a promising tool for mitigating such harms. To be specific, youth participation enables the youth to become well aware of the ground realities of their societies and the underlying policies. Through their participation, the youth also gain valuable information about their rights, options, responsibilities. All these opportunities in turn could help them to acquire mature and thoughtful decision-making skills and develop a sense of autonomy which would be necessary for becoming healthy and secure adults [40].

Corroborating such a hypothesis, a recent study in Israel [41] and another on San Francisco Youth Commission (USA) [42] demonstrate that the participation of disadvantaged youths in collective decision making allows them to acquire a sense of belonging. In a different participatory context, researchers have anticipated since the past decades $[43,44]$ that increased literacy and activism among the youth regarding climate change helps mitigate climate skepticism. And signs of progress have started to emerge, with a notable example being the recent climate strike by millions of youth across the world led by Greta Thunberg [27].

\section{CURRENT PROGRESS AND LIMITATIONS}

The need for promoting youth participation has long been emphasized by policy experts. Recent studies [6] rightly argue that the youth remain heavily underrepresented in the policy arena $[45,46]$. In response, international organizations such as the UN, the International Labour Organisation (ILO), the UN Development Programme (UNDP), and the World Bank have devised focussed measures to improve youth participation in the policy building process and have initiated numerous programs for direct youth involvement in collaboration with local governments, in recent years [34]. However, the extent of such efforts remains limited. The large-scale impact of youth in policy decisions remains to be seen. The youth organizations still lack political power and merely remain a form of representation [47]. Studies have also noted the systematic lack of institutional support of the youth [6]. In the absence of large-scale participation and impact, studies that argue for youth participation also remain suggestive rather than evidence-driven. A few case studies in the literature clearly quantify the advantage of youth participation, yet they remain limited with regard to the extent of institutional prescription and number. Progress has been made over the past decade, but the developments remain far from sufficient.

While we highlight the advantages and promises of youth participation in science policy, we acknowledge that youth participation involves its own set of challenges. For one thing, the diversity of the youth as a social group naturally presents a challenge of developing robust yet inclusive plans for promoting participation. Moreover, ensuring the democratic representation of various youth groups [49] and acceptance of their policy proposals $[12,19]$ remain a challenge to be addressed. Aside from the practical challenges, lack of empirical research on how and to what extent youth participation can make contributions at broader levels of participation remains as another big challenge. Some may argue at this point that there is no conclusive evidence to believe that the youth have the sufficient capacity and 


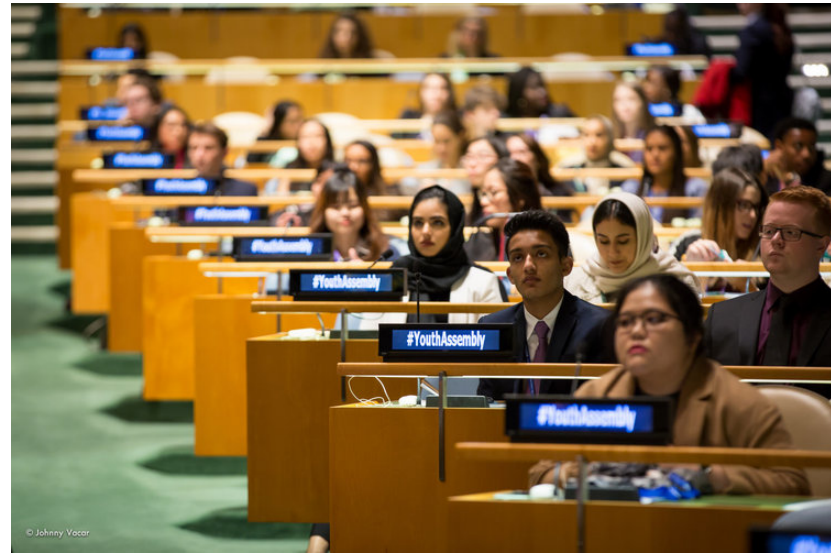

Figure 2: Youth Assembly at the United Nations 2017, photo credit: [48].

experience to make substantial contributions to science policy. While we do not necessarily disagree that some subcategories of the youth may lack the kinds of experience and knowledge specific to policy topics, we argue that such a lack could be translated into the advantage of having minimal professional biases and the ability to offer fresh perspectives. For instance, as discussed earlier, it may help to recognize that while youngsters in general can certainly contribute to and benefit from policy efforts in general, university students in particular would be capable of making substantial contributions to science policy. Thus, a systematic support from academic institutions and policy experts could help to establish a basis for governments to design and implement evidence-based policies that realize the potential of various sub-categories of the youth.

\section{CONCLUSION}

In this article, we have argued for fostering youth participation in science policy based on the recognition of the youth as a major policy stakeholder capable of making valuable contributions. Fostering youth participation has the potential to make policies more inclusive and democratic while helping the youth to develop their sense of autonomy and identity. Although youth involvement in science policy remains limited, we stress that the youth consist of diverse groups with different capabilities. In particular, university students are highly capable yet under-represented actors. Fortunately, national, international, governmental, as well as, non-governmental organisations have begun to increase their support at both individual and organizational levels. Thus, the better-equipped youth, namely university-students, have the opportunity to contribute to science policy issues. Though most of these initiatives are limited to developed nations such as the US. No doubt, promoting youth participation in policy and especially science policy is a challenge. However, with careful planning and support from policy experts and scholars, a path forward may be in place. It is time that serious efforts are made to increase youth participation in policy building. With approximately $40 \%$ of the world below
24 years of age [50], youth have every right to shape the environment they want to live in. Thus, governments and policy institutions ought to establish the participatory environment for the youth to become part and parcel of policy action. Simultaneously, meeting policy challenges essentially requires equal participation from the youth as no effort would be fruitful without meaningful response. As means of organization, participation, and communication become increasingly available, it would be up to the youth to make the most of the opportunities to build a more inclusive and thriving world.

\section{Acknowledgements}

This article was a collaborative work between the authors from the Massachusetts Institute of Technology and the Korea Advanced Institute of Science and Technology. The authors thank the editors from the MIT Science Policy Review and Behind Sciences (KAIST) for their feedback on the article.

\section{Citation}

Agarwal, S. \& Sung, R. D. On the landscape of youth participation in science policy. MIT Science Policy Review 2, 2-7 (2021). https://doi.org/10.38105/spr. 40 pp6vtbu1.

\section{Open Access}

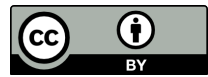

This MIT Science Policy Review article is licensed under a Creative Commons Attribution 4.0 International License, which permits use, sharing, adaptation, distribution and reproduction in any medium or format, as long as you give appropriate credit to the original author(s) and the source, provide a link to the Creative Commons license, and indicate if changes were made. The images or other third party material in this article are included in the article's Creative Commons license, unless indicated otherwise in a credit line to the material. If material is not included in the article's Creative Commons license and your intended use is not permitted by statutory regulation or exceeds the permitted use, you will need to obtain permission directly from the copyright holder. To view a copy of this license, visit http://creativecommons.org/licenses/ by $/ 4.0 /$.

\section{References}

[1] Science policy. Wikipedia. Online: https://en.wikipedia. org/wiki/Science_policy. Accessed on 10 August 2021.

[2] Evenson, R. E. \& Gollin, D. Assessing the impact of the green revolution, 1960 to 2000. Science 300, 758-762 (2003).

[3] Rappuoli, R., Mandl, C. W., Black, S. \& De Gregorio, E. Vaccines for the twenty-first century society. Nature Reviews Immunology 11, 865-872 (2011).

[4] Back from the brink: How the world rapidly sealed a deal to save the ozone layer. Online: https://www.rapidtransition. org/stories/back-from-the-brink-how-the-worldrapidly-sealed-a-deal-to-save-the-ozone-layer/. Accessed on 10 August 2021.

[5] Betsch, C. et al. Social and behavioral consequences of mask policies during the COVID-19 pandemic. Proceedings of the National Academy of Sciences 117, 21851-21853 (2020).

[6] Palmy David, N. \& Buchanan, A. Planning our future: Institutionalizing youth participation in local government planning efforts. Planning Theory \& Practice 21, 9-38 (2020). 
[7] Zeldin, S., McDaniel, A. K., Topitzes, D. \& Calvert, M. Youth in decision-making: A study on the impacts of youth on adults and organizations (2000).

[8] Scheve, J. A., Perkins, D. F. \& Mincemoyer, C. Collaborative teams for youth engagement. Journal of Community Practice 14, 219-234 (2006).

[9] Definition of youth. United Nations. Online: https: //www.un.org/esa/socdev/documents/youth/factsheets/youth-definition.pdf. Accessed on 10 August 2021.

[10] Urbinati, N. Representative democracy (University of Chicago Press, 2008).

[11] Gidfar, M. 20 years of data reveals that congress doesn't care what you think. Upworthy (2015). Online: https: //www. upworthy.com/20-years-of-data-revealsthat-congress-doesnt-care-what-you-think. Accessed on 10 August 2021.

[12] Gilens, M. \& Page, B. I. Testing theories of American politics: Elites, interest groups, and average citizens. Perspectives on politics 12, 564-581 (2014).

[13] McElwee, S. To influence policy, you have to be more than rich. Washington Monthly (2016). Online: https://washingtonmonthly.com/2016/02/16/toinfluence-policy-you-have-to-be-more-thanrich/. Accessed on 10 August 2021

[14] Lindsey, B. \& Teles, S. M. The captured economy: How the powerful enrich themselves, slow down growth, and increase inequality (Oxford University Press, 2017).

[15] Kempf, H. How the rich are destroying the earth (Chelsea Green Publishing Company, 2008).

[16] Riemer, H., Shavitt, S., Koo, M. \& Markus, H. R. Preferences don't have to be personal: Expanding attitude theorizing with a cross-cultural perspective. Psychological review 121, 619 (2014).

[17] Freeman, M. Children's rights as human rights: Reading the uncrc. In The Palgrave handbook of childhood studies, 377-393 (Springer, 2009).

[18] Derr, V., Sitzoglou, M., Gülgönen, T. \& Corona, Y. Integrating children and youth participation into resilience planning. Canadian Journal of Children's Rights/Revue canadienne des droits des enfants 5, 173-199 (2018).

[19] Chawla, L. et al. Welcoming young people in urban placemaking: Learning from challenges. The Routledge Handbook of Designing Public Spaces for Young People 120-134 (2020).

[20] Derr, V., Chawla, L. \& Mintzer, M. Placemaking with children and youth: Participatory practices for planning sustainable communities (New Village Press, 2018).

[21] Stacy, S. T., Castro, K. M. \& Acevedo-Polakovich, I. D. The cost of youth voices: Comparing the feasibility of youth go against focus groups. Journal of Participatory Research Methods 1, 13312 (2020)

[22] van der Velde, T. et al. Comparison of marine debris data collected by researchers and citizen scientists: Is citizen science data worth the effort? Biological conservation 208, 127-138 (2017).

[23] Fernandez, G. \& Shaw, R. Youth council participation in disaster risk reduction in infanta and makati, philippines: A policy review. International Journal of Disaster Risk Science 4, 126-136 (2013).

[24] Cumiskey, L., Hoang, T., Suzuki, S., Pettigrew, C. \& Herrgård, M. M. Youth participation at the third un world conference on disaster risk reduction. International Journal of Disaster Risk Science 6, 150-163 (2015).

[25] Botchwey, N., O'Connell, L. K., Bryan, K. \& Ricks, T. Successful youth advocacy (ya) programs: Lessons from yeah adult leaders evaluation study from across the country. Journal of Healthy Eating and Active Living 1, 41-52 (2021).

[26] Ballard, H. L., Dixon, C. G. \& Harris, E. M. Youth-focused citizen science: Examining the role of environmental science learning and agency for conservation. Biological Conservation 208, 65-75 (2017).
[27] Greta thunberg effect: people familiar with young climate activist may be more likely to act. The Conversation (2021). Online: https://theconversation.com/greta-thunbergeffect-people-familiar-with-young-climateactivist-may-be-more-likely-to-act-154146. Accessed on 10 August 2021.

[28] History of youngo. YOUNGO (2021). Online: http://www. youngo. uno/about/history. Accessed on 10 August 2021.

[29] Disarmament education: The role of survivors and youth United Nations (2016). Online: https://www.un.org/ disarmament/update/disarmament-education-therole-of-survivors-and-youth/. Accessed on 10 August 2021.

[30] 500 women scientists. Online: https:// 500 womenscientists.org/. Accessed on 10 August 2021.

[31] Graduate student groups from 15 states awarded for science policy initiatives to engage. EurekAlert! (2021). Online: https : //www. eurekalert.org/news-releases/550762. Accessed on 10 August 2021.

[32] Nevins, C. J. Engaging with science policy as a grad student CSA News 63, 39-41 (2018).

[33] Photo credits: N jilderda. Pexels.com. Online: https://www . pexels.com/photo/crowd-of-peoplemarching-on-a-rally-2975498/. Accessed on 10 August 2021.

[34] Kwon, S. A. The politics of global youth participation. Journal of Youth Studies 22, 926-940 (2019).

[35] Banjac, M. Youth, risk and the structured dialogue: governing young eu citizens. Journal of Youth Studies 20, 471-486 (2017).

[36] Peery, M. Z. et al. The conundrum of agenda-driven science in conservation (2019)

[37] Anderson, A. Media, politics and climate change: Towards a new research agenda. Sociology compass 3, 166-182 (2009).

[38] Boydstun, A. E. Making the news: Politics, the media, and agenda setting (University of Chicago Press, 2013).

[39] Lazer, D. M. et al. The science of fake news. Science 359 , 1094-1096 (2018).

[40] Augsberger, A., Collins, M. E. \& Gecker, W. Engaging youth in municipal government: Moving toward a youth-centric practice. Journal of Community Practice 26, 41-62 (2018).

[41] Gazit, M. \& Perry-Hazan, L. Disadvantaged youth's participation in collective decision making. Children and Youth Services Review 110, 104759 (2020).

[42] Checkoway, B., Allison, T. \& Montoya, C. Youth participation in public policy at the municipal level. Children and youth services review 27, 1149-1162 (2005).

[43] Harker-Schuch, I., Lade, S., Mills, F. \& Colvin, R. Opinions of 12 to 13-year-olds in Austria and Australia on the concern, cause and imminence of climate change. Ambio 50, 644-660 (2021).

[44] Stevenson, K. T., Peterson, M. N., Bondell, H. D., Moore, S. E. \& Carrier, S. J. Overcoming skepticism with education: interacting influences of worldview and climate change knowledge on perceived climate change risk among adolescents. Climatic change 126, 293-304 (2014).

[45] Sutton, S. E. \& Kemp, S. P. Children as partners in neighborhood placemaking: lessons from intergenerational design charrettes. Journal of Environmental Psychology 22, 171-189 (2002).

[46] Dennis Jr, S. F. Prospects for qualitative gis at the intersection of youth development and participatory urban planning. Environment and Planning A 38, 2039-2054 (2006).

[47] Corrie, E. W. Fear and loathing: The rise of ephebiphobia and its implications for youth activism. In Four Dead in Ohio (Emerald Publishing Limited, 2021).

[48] Photo credits: Johney vacar, courtesy, united nations - faf.org - the youth assembly. Online: https: //images.squarespace-cdn.com/content/v1/ 54 e4862de4b0004c775a3d5a/1497249210063AHEJIAJ650RDJ8E91D02/Youth+Assembly+at+the+ United+Nations+2017. Accessed on 10 August 2021. 
[49] Dalton, R. J. The participation gap: Social status and political inequality (Oxford University Press, 2017).

[50] Chart: How is the world's youth population changing? Worldbank (2017). Online: https://theconversation.com/gretathunberg-effect-people-familiar-with-young-

climate-activist-may-be-more-likely-to-act154146. Accessed on 10 August 2021. 